\title{
Malikia granosa gen. nov., sp. nov., a novel polyhydroxyalkanoate- and polyphosphate- accumulating bacterium isolated from activated sludge, and reclassification of Pseudomonas spinosa as Malikia spinosa comb. nov.
}

\author{
Correspondence \\ Stefan Spring \\ ssp@dsmz.de
}

\author{
Stefan Spring, ${ }^{1}$ Michael Wagner, ${ }^{2}$ Peter Schumann ${ }^{1}$ and Peter Kämpfer ${ }^{3}$ \\ 'DSMZ - Deutsche Sammlung von Mikroorganismen und Zellkulturen, Mascheroder Weg 1b, \\ D-38124 Braunschweig, Germany \\ ${ }^{2}$ Abteilung für Mikrobielle Ökologie, Institut für Ökologie und Naturschutz (IECB), Universität \\ Wien, Althanstr. 14, A-1090 Vienna, Austria \\ ${ }^{3}$ Institut für Angewandte Mikrobiologie, Justus-Liebig-Universität Giessen, Heinrich-Buff-Ring \\ 26-32 (IFZ), D-35392 Giessen, Germany
}

\begin{abstract}
A Gram-negative, motile, rod-shaped bacterium, designated strain $\mathrm{P}^{\top}{ }^{\top}$, was isolated from activated sludge of a municipal wastewater treatment plant. Phylogenetic analysis of its $16 \mathrm{~S}$ rRNA gene sequence placed the novel isolate among representatives of the family Comamonadaceae. The closest relatives in reconstructed phylogenetic trees were Pseudomonas spinosa, Macromonas bipunctata and Hydrogenophaga species. Strain $\mathrm{P} 1^{\top}$ was not able to grow anaerobically or autotrophically, reduced nitrate to nitrite and required vitamins for growth. Ubiquinone 8 (Q8) and 3-hydroxy-substituted fatty acids were present, but 2-hydroxy fatty acids were absent. The $\mathrm{G}+\mathrm{C}$ content of the DNA was $67 \mathrm{~mol} \%$. Phenotypic characteristics allowed a clear differentiation of strain $\mathrm{P} 1^{\top}$ from representatives of the genera Hydrogenophaga and Macromonas, whereas DNA-DNA hybridization experiments revealed that strain $\mathrm{P} 1^{\top}$ did not belong to the species $P$. spinosa. As a peculiarity, cells of strain $\mathrm{P}^{\top}{ }^{\top}$ and $P$. spinosa ATCC $14606^{\top}$ were able to accumulate large amounts of polyhydroxyalkanoates and polyphosphate in the form of large intracellular granules. Apparently in both strains nitrogen limitation stimulates the production of polyhydroxyalkanoates, whereas carbon starvation induces the formation of polyphosphates. Based upon phylogenetic and phenotypic evidence, it is proposed to establish the novel taxon Malikia granosa gen. nov., sp. nov., represented by the type strain $\mathrm{P}^{\top}{ }^{\top}$ (=DSM $15619^{\top}=$ JCM $12706^{\top}=$ CIP $108194^{\top}$ ). The most closely related species of strain $\mathrm{P} 1^{\top}$ was $P$. spinosa. This species has been misclassified, and it is proposed to transfer it to the new genus Malikia as Malikia spinosa gen. nov., comb. nov. The type strain is ATCC $14606^{\top}$ (=DSM $15801^{\top}$ ).
\end{abstract}

Since 1993 several studies applying cultivation-independent techniques have demonstrated that members of the $\beta$ Proteobacteria, especially the family Comamonadaceae, may represent a major fraction of the metabolically active

Published online ahead of print on 4 October 2004 as DOI 10.1099/ ijs.0.63356-0.

Abbreviations: EBPR, enhanced biological phosphorus removal; PAO, phosphate-accumulating organism; $\mathrm{PHA}$, polyhydroxyalkanoate; poly- $\mathrm{P}$, polyphosphate.

The GenBank/EMBL/DDBJ accession number for the 16S rRNA gene sequence of strain $\mathrm{P}^{\top}{ }^{\top}$ is AJ627188.

Additional micrographs and an unrooted phylogenetic tree are available as supplementary material in IJSEM Online. microbial population in activated sludge of municipal sewage-treatment plants (Wagner et al., 1993, 1994b; Manz et al., 1994; Wallner et al., 1995; Snaidr et al., 1997; Wagner \& Amann, 1997; Wagner \& Loy, 2002). Several filamentous $\beta$-Proteobacteria contribute to bulking problems of activated sludge (Wagner et al., 1994a) whereas other $\beta$ Proteobacteria catalyse, for example, aerobic ammonia oxidation (Purkhold et al., 2000; Juretschko et al., 2002), denitrification (Ginige et al., 2004) or the removal of phosphorous from sewage (Lee et al., 1999, 2003; Hesselmann et al., 1999; Blackall et al., 2002). However, cultivation-independent methods that are based solely on phylogenetic sequence information are not adequate to reveal an encompassing picture of the physiology of these 
micro-organisms in the environment. In particular, bacteria belonging to the family Comamonadaceae and neighbouring phylogenetic groups are phenotypically highly diverse, even if they are phylogenetically closely related, such that it is very difficult to correlate a distinct phylotype found in the environment with a certain metabolic potential of a related recognized species.

Two approaches have been developed to overcome these limitations in studying the physiological potential of distinct bacterial phylotypes in sewage sludge. Lee et al. (1999) and Ouverney \& Fuhrman (1999) introduced a novel tool in microbial ecology by combining the oligonucleotidebased fluorescence in situ hybridization (FISH) of single cells with a high-resolution measurement of the microbial substrate uptake pattern using microautoradiography. A less laborious approach is based on screening of novel isolates retrieved from the studied environment with oligonucleotide probes targeting a specific group of microorganisms. Pure cultures of the strains obtained can then be studied ex situ by applying standard microbial methods. An oligonucleotide-probe-assisted directed cultivation procedure has been successfully applied to samples of activated sludge and led to the characterization of several novel species (Schulze et al., 1999; Spring et al., 2004; Kämpfer et al., 2005).

The oligonucleotide probe LDI23a (Wagner et al., 1994a), specific for Leptothrix discophora and several related species within the Comamonadaceae, was used for the targeted isolation of novel $\beta$-Proteobacteria from activated sludge of a large municipal wastewater treatment plant (München I; Großlappen, Germany). Probe LDI23a was chosen because in the high-load aeration basin of this plant abundant bacteria hybridizing with this probe in situ were observed by FISH. Screening of isolates using this probe identified two novel strains. The complete isolation procedure and characterization of one of these strains have been described previously by Spring et al. (2004). A polyphasic characterization of the second strain, designated $\mathrm{P}^{\mathrm{T}}$, is presented here.

Standard microbial methods, as reported previously by Spring et al. (2001, 2004), were used for the phenotypic characterization of the newly isolated strain $\mathrm{P}^{\mathrm{T}}$ and of Pseudomonas spinosa ATCC $14606^{\mathrm{T}}$, obtained from American Type Culture Collection (ATCC; Manassas, VA, USA). P. spinosa was chosen for a comparative characterization because it represents the phylogenetically most closely related species and the description provided by Leifson (1962) is rather sparse. Unless stated otherwise, R2A medium (Reasoner \& Geldreich, 1985) was used for growth experiments. Cells were Gram-negative, straight to slightly curved rods with rounded ends (Fig. 1a). They occurred singly or in short chains and were motile by means of one to two polar flagella. Filamentous cells up to $50 \mu \mathrm{m}$ in length were frequently observed in nutrientrich media. Under conditions of nitrogen limitation highly refractile intracellular granules could be observed

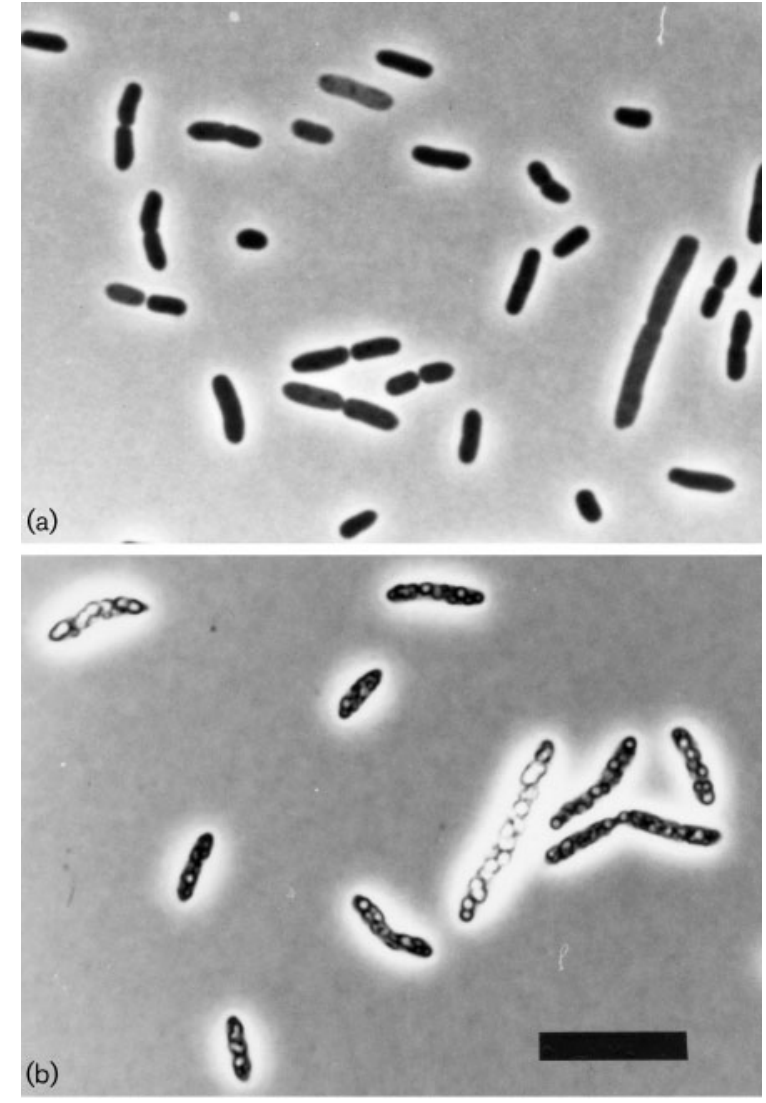

Fig. 1. Phase-contrast micrographs of strain $P 1^{\top}$ demonstrating the accumulation of PHA in the form of refractile granules under conditions of nitrogen limitation. (a) Growth in modified SFW medium containing $2.0 \mathrm{~g}$ acetate $\mathrm{I}^{-1}$ and $0.4 \mathrm{~g} \mathrm{NH}_{4} \mathrm{Cl} \mathrm{I}^{-1}$; (b) growth in modified SFW medium containing $2.0 \mathrm{~g}$ acetate $\mathrm{I}^{-1}$ without added $\mathrm{NH}_{4} \mathrm{Cl}$. Bar, $10 \mu \mathrm{m}$.

by phase-contrast microscopy. After prolonged incubation in media that contained only very low concentrations of bound nitrogen, cells appeared slightly swollen and were almost completely filled with these granules (Fig. 1b). Storage inclusions consisted of polyhydroxyalkanoates (PHAs), which could be demonstrated by staining with Nile Blue (Ostle \& Holt, 1982). An epifluorescence micrograph demonstrating the typical bright red-orange fluorescence of the PHA granules after staining with Nile Blue is available as supplementary Fig. A in IJSEM Online.

Storage of polyphosphate (poly-P) as reserve material in cells of strain $\mathrm{P}^{\mathrm{T}}$ was shown by Neisser staining according to the protocol of Jenkins et al. (1993). Both kinds of reserve polymers could also be detected in the closely related strain P. spinosa ATCC $14606^{\mathrm{T}}$.

Colonies of strain $\mathrm{P}^{\mathrm{T}}$ appeared after $24 \mathrm{~h}$ on $\mathrm{R} 2 \mathrm{~A}$ agar. They reached about $2 \mathrm{~mm}$ in diameter after 2 days incubation. After several days colonies appeared mucoid as a result of the formation of extracellular slime. No diffusible pigments were formed. 
The newly isolated strain grew well at temperatures ranging from 5 to $40{ }^{\circ} \mathrm{C}$ (temperatures below $5{ }^{\circ} \mathrm{C}$ were not tested). The $\mathrm{pH}$ range for growth in buffered $\mathrm{R} 2 \mathrm{~A}$ broth was $6 \cdot 0-9 \cdot 0$. Adaptation of strain $\mathrm{P} 1^{\mathrm{T}}$ to freshwater habitats is reflected in its low salt tolerance. $\mathrm{NaCl}$ is tolerated in the medium only up to a concentration of $0.5 \%(\mathrm{w} / \mathrm{v})$. Under optimal growth conditions $\left(35^{\circ} \mathrm{C}, \mathrm{pH} 7 \cdot 0\right)$ the doubling time of $\mathrm{P}^{\mathrm{T}}$ was $1 \cdot 2 \mathrm{~h}$. The growth characteristics of P. spinosa ATCC $14606^{\mathrm{T}}$ were similar to $\mathrm{P}^{\mathrm{T}}$ with only marginal differences; these are explicitly given in the formal species descriptions below.

The spectrum of usable carbon sources was determined in a microplate assay as described by Kämpfer et al. (1991) with the modification that the final substrate concentrations were $0 \cdot 1 \%(\mathrm{w} / \mathrm{v})$. Strain $\mathrm{P}^{\mathrm{T}}$ was able to utilize a broad range of different substrates as sole carbon sources, including carbohydrates, sugar alcohols and organic acids. Formation of PHA granules was not restricted to a specific substrate, but acetate was particularly suitable to demonstrate its accumulation in this strain. In contrast, the substrate utilization pattern of $P$. spinosa ATCC $14606^{\mathrm{T}}$ was more limited and restricted to a few carbohydrates and organic acids.

Chemolithoautotrophic growth of the novel strain $\mathrm{P}^{\mathrm{T}}$ and $P$. spinosa ATCC $14606^{\mathrm{T}}$ with hydrogen as substrate was tested under the conditions described by Malik \& Schlegel (1981) for the cultivation of various Knallgas bacteria. As a trait that distinguishes both strains from most species of the closely related genus Hydrogenophaga, no aerobic autotrophic growth with hydrogen as substrate was detected. Thiosulfate was not utilized as substrate and did not support autotrophic or chemolithoheterotrophic growth. In contrast, two species of the genus Hydrogenophaga, Hydrogenophaga palleronii and Hydrogenophaga intermedia, were shown to oxidize thiosulfate to sulfate (Kämpfer et al., 2005).

Strains $\mathrm{P} 1^{\mathrm{T}}$ and P. spinosa ATCC $14606^{\mathrm{T}}$ were both oligonitrophilic and could grow in liquid mineral medium with $0 \cdot 1 \mathrm{~g}$ yeast extract $1^{-1}$ as the only source of bound nitrogen. Fixing of molecular nitrogen, however, could not be demonstrated. No growth was observed under anaerobic conditions. Nitrate was reduced to nitrite, but denitrification did not occur. Neither strain was able to grow phototrophically.

Further details of the morphological and physiological characterization of strain $\mathrm{P}^{\mathrm{T}}$ and P. spinosa ATCC $14606^{\mathrm{T}}$ are given in Table 1 and in the formal species descriptions below.

Analysis of the respiratory lipoquinones of strains $\mathrm{P} 1^{\mathrm{T}}$ and P. spinosa ATCC $14606^{\mathrm{T}}$ was by HPLC and electronimpact mass spectrometry according to the methods of Monciardini et al. (2003); ubiquinone-8 (Q-8) was the predominant component in both strains. This quinone system is a characteristic feature of the $\beta$-Proteobacteria
(Yokota et al., 1992). The cellular fatty acid composition of both strains was analysed after growth on R2A agar and TSA plates (Difco) and compared with the fatty acid pattern of Macromonas bipunctata DSM $12705^{\mathrm{T}}$, the only available pure culture of the genus Macromonas (Table 2). Fatty acid methyl esters were extracted and prepared by the standard protocol of the Microbial Identification System (MIDI, Microbial ID). Extracts were analysed by GLC as described by Kämpfer \& Kroppenstedt (1996) and Kämpfer et al. (1997). The fatty acid profiles of strains $P 1^{\mathrm{T}}$ and P. spinosa ATCC $14606^{\mathrm{T}}$ were very similar but distinguishable. In general, the patterns of both strains were typical for members of the Comamonadaceae and were dominated by the unbranched fatty acids $16: 1 \omega 7 c(54-71 \%), 16: 0$ (15$25 \%)$ and $18: 1 \omega 7 c(6-12 \%)$. The abundance of distinct fatty acids depended largely on the incubation conditions. For example, in both strains the hydroxylated fatty acid 8:0 3-OH was only detected after incubation on TSA plates. One possible reason for this effect could be the much higher protein content of TSA medium compared to R2A agar. Significant differences were found for the fatty acid profile of Macromonas bipunctata DSM $12705^{\mathrm{T}}$, which was dominated by unsaturated fatty acids $16: 1 \omega 7 \mathrm{c}$, $17: 1 \omega 6 c$ and $18: 1 \omega 7 c$, whereas $16: 0$ was present only in minor amounts.

A comparison of the fatty acid profiles obtained with the overall fatty acid composition of the genus Hydrogenophaga is shown in Table 2. The large number of type strains belonging to this genus makes detailed comparison with related taxa consisting of only one or two strains difficult. Nevertheless, the occurrence of the cyclo propane fatty acid 17:0 cyclo among Hydrogenophaga species could be used to distinguish it from its most closely related taxa.

The 16S rRNA gene of strain $\mathrm{P1}^{\mathrm{T}}$ was amplified and sequenced as reported by Spring et al. (2001). A continuous stretch of $1525 \mathrm{nt}$ of the $16 \mathrm{~S}$ rRNA gene sequence of strain $\mathrm{P} 1^{\mathrm{T}}$ was determined and used for a comparative phylogenetic analysis applying the ARB software package, including a current release of the small-subunit rRNA database (Ludwig et al., 2004). An ARB parsimony analysis placed strain $\mathrm{P} 1^{\mathrm{T}}$ within the family Comamonadaceae of the $\beta$-Proteobacteria. In various phylogenetic trees reconstructed by using neighbour-joining, maximum-likelihood or maximum-parsimony methods, the nearest relatives of strain $\mathrm{P}^{\mathrm{T}}$ were Hydrogenophaga species, Macromonas bipunctata and P. spinosa. In most of the reconstructed trees these bacteria formed a coherent lineage supported by bootstrap values of $80 \%$ or greater. A representative phylogenetic tree including bootstrap values is shown in Fig. 2. In this tree, which is based on only a limited number of sequences representing mainly type species of the Comamonadaceae, some members of the genus Hydrogenophaga form a common branch with strain $\mathrm{P}^{\mathrm{T}}, P$. spinosa and Macromonas bipunctata. However, when extensive datasets were used for tree reconstruction that comprise all available, nearly complete $16 \mathrm{~S}$ rRNA gene sequences 
Table 1. Differential characteristics of the genus Malikia and closely related genera in the family Comamonadaceae

All type strains of the genera listed have a rod-shaped morphology, are oxidase- and catalase-positive, are able to grow at $35^{\circ} \mathrm{C}$, and accumulate PHAs and poly-P as reserve polymers. Symbols: + , present in all type strains; -, absent from all type strains; d, 11-89\% of type strains positive; ND, not determined. Data for the genera Hydrogenophaga and Macromonas were taken from Kämpfer et al. (2005) and Dubinina \& Grabovich (1984), respectively.

\begin{tabular}{|c|c|c|c|}
\hline Characteristic & Malikia & Hydrogenophaga & Macromonas \\
\hline No. of species $(n)$ & 2 & 7 & $2^{*}$ \\
\hline Cell diameter $(\mu \mathrm{m})$ & $1 \cdot 1-1 \cdot 3$ & $0 \cdot 3-0 \cdot 6$ & $2 \cdot 2-4 \cdot 5$ \\
\hline Flagella & $1-3$, polar & 1, polar & Polar tuft \\
\hline PHA accumulation induced by $\mathrm{N}$ limitation & + & + & - \\
\hline Non-diffusible pigments & - & + & - \\
\hline Slime formation on R2A agar & + & - & - \\
\hline Autotrophic growth with $\mathrm{H}_{2}$ & - & $\mathrm{d}$ & - \\
\hline Reduction of $\mathrm{NO}_{3}^{-}$ & + & $\mathrm{d}$ & - \\
\hline Reduction of $\mathrm{NO}_{2}^{-}$ & - & $\mathrm{d}$ & - \\
\hline Oxidation of $\mathrm{S}_{2} \mathrm{O}_{3}^{2-}$ & - & $\mathrm{d}$ & $-\dagger$ \\
\hline Growth factors required & + & - & + \\
\hline \multicolumn{4}{|l|}{ Utilization of: } \\
\hline D-Fructose & - & $\mathrm{d}$ & - \\
\hline D-Glucose & + & $\mathrm{d}$ & - \\
\hline Formate & - & $\mathrm{d}$ & + \\
\hline Acetate & $\mathrm{d}$ & - & + \\
\hline Fumarate & $\mathrm{d}$ & $\mathrm{d}$ & + \\
\hline DL-Lactate & $\mathrm{d}$ & + & + \\
\hline Glycerol & - & + & - \\
\hline D-Mannitol & - & d & $\mathrm{ND}$ \\
\hline Major 3-OH fatty acids & $8: 0$ & $8: 0$ or $10: 0$ & $8: 0$ \\
\hline DNA $\mathrm{G}+\mathrm{C}$ content $(\mathrm{mol} \%)$ & $66-67$ & 64-69 & 68 \\
\hline
\end{tabular}

${ }^{*}$ Data for this genus are based on the type strain of the only available species, Macromonas bipunctata. The type species of the genus, Macromonas mobilis, is not available in pure culture.

$\dagger$ Thiosulfate oxidation by cells of Macromonas bipunctata is due to chemical oxidation by $\mathrm{H}_{2} \mathrm{O}_{2}$ (Dubinina \& Grabovich, 1984).

affiliated to the Comamonadaceae, strain $\mathrm{P}^{\mathrm{T}}$ was located on a common lineage together with P. spinosa and Macromonas bipunctata, but separated from Hydrogenophaga species (this tree is available as supplementary Fig. B in IJSEM Online). The phylogenetically most closely related species to strain $\mathrm{P}^{\mathrm{T}}$, based on $16 \mathrm{~S}$ rRNA gene sequence similarity values, was $P$. spinosa $(98 \cdot 4 \%)$. This species can be regarded as misclassified, because it is phylogenetically only distantly related to Pseudomonas aeruginosa, the type species of the genus. 16S rRNA gene sequence similarity values between $\mathrm{P}^{\mathrm{T}}$ and the other closely related taxa that form a common phylogenetic branch in Fig. 2 ranged from $95 \cdot 3$ to $96.9 \%$.

Genomic DNA for the determination of DNA base composition and DNA-DNA hybridization experiments was isolated using a French pressure cell and purified by chromatography on hydroxyapatite as described by Cashion et al. (1977). The G $+\mathrm{C}$ content of the total DNA of strain
$\mathrm{P}^{\mathrm{T}}$ and P. spinosa ATCC $14606^{\mathrm{T}}$ was 67 and $66 \mathrm{~mol} \%$, respectively. DNA-DNA hybridization experiments between both strains were carried out in $2 \times$ SSC buffer containing $10 \%$ DMSO at $70{ }^{\circ} \mathrm{C}$ according to the method of De Ley et al. (1970). DNA renaturation rates were measured using a Gilford System 2600 spectrophotometer (Gilford Instrument Laboratories) equipped with a Gilford 2527-R thermoprogrammer and plotter. The estimated level of DNA-DNA binding between strains $\mathrm{P}^{\mathrm{T}}$ and $P$. spinosa ATCC $14606^{\mathrm{T}}$ was $53 \%$, indicating that both strains represent distinct species.

A peculiarity of the novel strain $\mathrm{P} 1^{\mathrm{T}}$ and $P$. spinosa ATCC $14606^{\mathrm{T}}$ was the intracellular accumulation of PHAs and poly-P. Micro-organisms that are able to store these compounds in large amounts are thought to play a major role in the enhanced biological phosphorus removal (EBPR) process of specially designed wastewater treatment plants, which treat the sewage by alternating exposure to anaerobic 
Table 2. Fatty acid pattern of the novel strain $\mathrm{P} 1^{\top}$ compared to patterns of $P$. spinosa ATCC $14606^{\top}$, Macromonas bipunctata DSM $12705^{\top}$ and representatives of the genus Hydrogenophaga

Strains $\mathrm{P} 1^{\mathrm{T}}$ and $P$. spinosa ATCC $14606^{\mathrm{T}}$ were incubated on either R2A agar or TSA plates (Difco) at $28^{\circ} \mathrm{C}$ for $24 \mathrm{~h}$, whereas Macromonas bipunctata DSM $12705^{\mathrm{T}}$ was incubated only on R2A agar for 7 days prior to fatty acid analysis. The Hydrogenophaga type strains were incubated on TSA plates at $28{ }^{\circ} \mathrm{C}$ for $48 \mathrm{~h}$. Values are percentages of total fatty acids. Gaps indicate that the fatty acid was not detected. The three major fatty acids are given in bold type. The position of the double bond in unsaturated fatty acids is located by counting from the methyl $(\omega)$ end of the carbon chain; cis and trans isomers are indicated by the suffixes $c$ and $t$, respectively. Abbreviations: tr, trace; cyc, cyclopropane; alde, aldehyde.

\begin{tabular}{|c|c|c|c|c|c|c|}
\hline \multirow[t]{2}{*}{ Fatty acid } & \multicolumn{2}{|c|}{$\mathbf{P} 1^{\mathrm{T}}$} & \multicolumn{2}{|c|}{ P. spinosa } & \multirow{2}{*}{$\frac{\text { Macromonas bipunctata }}{\mathrm{R} 2 \mathrm{~A}}$} & \multirow{2}{*}{$\frac{\text { Hydrogenophaga }}{\text { TSA }}$} \\
\hline & R2A & TSA & R2A & TSA & & \\
\hline \multicolumn{7}{|l|}{ Saturated fatty acids } \\
\hline $9: 0$ & & & & & $0 \cdot 2$ & $0-0 \cdot 1$ \\
\hline $10: 0$ & & & & $0 \cdot 1$ & & $0-\operatorname{tr}$ \\
\hline $11: 0$ & & & & & & $0-0 \cdot 9$ \\
\hline $12: 0$ & & & & & & $0-6 \cdot 0$ \\
\hline $13: 0$ & & & & & & $0-1 \cdot 7$ \\
\hline $14: 0$ & $1 \cdot 4$ & $1 \cdot 2$ & $1 \cdot 1$ & $1 \cdot 7$ & $2 \cdot 4$ & $0-3 \cdot 6$ \\
\hline $15: 0$ & & $3 \cdot 2$ & & & $1 \cdot 2$ & $0-4 \cdot 9$ \\
\hline $16: 0$ & $14 \cdot 7$ & $19 \cdot 9$ & $25 \cdot 0$ & $14 \cdot 8$ & $5 \cdot 3$ & $2 \cdot 3-42 \cdot 9$ \\
\hline $17: 0$ & & $0 \cdot 9$ & & & $0 \cdot 8$ & $0 \cdot 2-6 \cdot 6$ \\
\hline $18: 0$ & & & & & & $0-0 \cdot 7$ \\
\hline \multicolumn{7}{|c|}{ Unsaturated fatty acids } \\
\hline $15: 1 \omega 6 c$ & & & & & $0 \cdot 9$ & $0-14 \cdot 8$ \\
\hline $16: 1 \omega 5 c$ & $3 \cdot 2$ & $1 \cdot 3$ & $1 \cdot 7$ & $2 \cdot 7$ & $1 \cdot 1$ & $0-0 \cdot 6$ \\
\hline $16: 1 \omega 7 c$ & $71 \cdot 0$ & $53 \cdot 9$ & $57 \cdot 9$ & $71 \cdot 1$ & $62 \cdot 5$ & $16 \cdot 2-51 \cdot 1$ \\
\hline $17: 1 \omega 6 c$ & & $3 \cdot 8$ & & & $12 \cdot 5$ & $0-20 \cdot 4$ \\
\hline $17: 1 \omega 8 c$ & & $1 \cdot 3$ & & & $1 \cdot 1$ & $0-2 \cdot 6$ \\
\hline $18: 1 \omega 7 c$ & $6 \cdot 3$ & $10 \cdot 4$ & $12 \cdot 8$ & $6 \cdot 9$ & $11 \cdot 9$ & $9 \cdot 8-25 \cdot 6$ \\
\hline \multicolumn{7}{|l|}{ Hydroxy fatty acids } \\
\hline $8: 03-\mathrm{OH}$ & & $2 \cdot 7$ & & $2 \cdot 8$ & $0 \cdot 2$ & $0-3 \cdot 8$ \\
\hline $9: 03-\mathrm{OH}$ & & $0 \cdot 5$ & & & & $0-1 \cdot 0$ \\
\hline $10: 03-\mathrm{OH}$ & & & & & & $0-3 \cdot 2$ \\
\hline $16: 03-\mathrm{OH}$ & & & & & & $0-0 \cdot 3$ \\
\hline \multicolumn{7}{|l|}{ Cyclo propane acids } \\
\hline $17: 0$ сус & & & & & & $0-17 \cdot 2$ \\
\hline $19: 0$ сус $\omega 8 c$ & & & & & & $0-1 \cdot 5$ \\
\hline \multicolumn{7}{|c|}{ Branched chain fatty acids } \\
\hline $16: 0$ iso & & & & & & $0-0 \cdot 7$ \\
\hline $19: 0$ iso & & & & & & $0-1 \cdot 6$ \\
\hline \multicolumn{7}{|l|}{ Summed features ${ }^{*}$} \\
\hline Summed feature 2 & & & & $\operatorname{tr}$ & & \\
\hline Summed feature 7 & $2 \cdot 3$ & $1 \cdot 1$ & $1 \cdot 6$ & & $0 \cdot 3$ & \\
\hline
\end{tabular}

*Summed features represent groups of two or three fatty acids that could not be separated by GLC with the MIDI system. Summed feature 2 contained one or more of the following fatty acids: 12:0 alde, 16:1 iso I

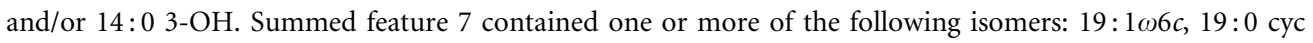
and/or an unknown compound with the equivalent chain-length $18 \cdot 846$.

and aerobic conditions (Blackall et al., 2002; Serafim et al., 2002). According to current models of this process (Seviour et al., 2003) extracellular phosphorus is removed from the wastewater by phosphate-accumulating organisms (PAOs) that take up phosphorus under aerobic conditions and store it as poly-P. Under anaerobic conditions the accumulated poly-P is degraded to provide energy for the PAOs to assimilate organic substances and to synthesize PHAs, which again serve under aerobic conditions (in the absence of extracellular organic compounds) as carbon and energy 


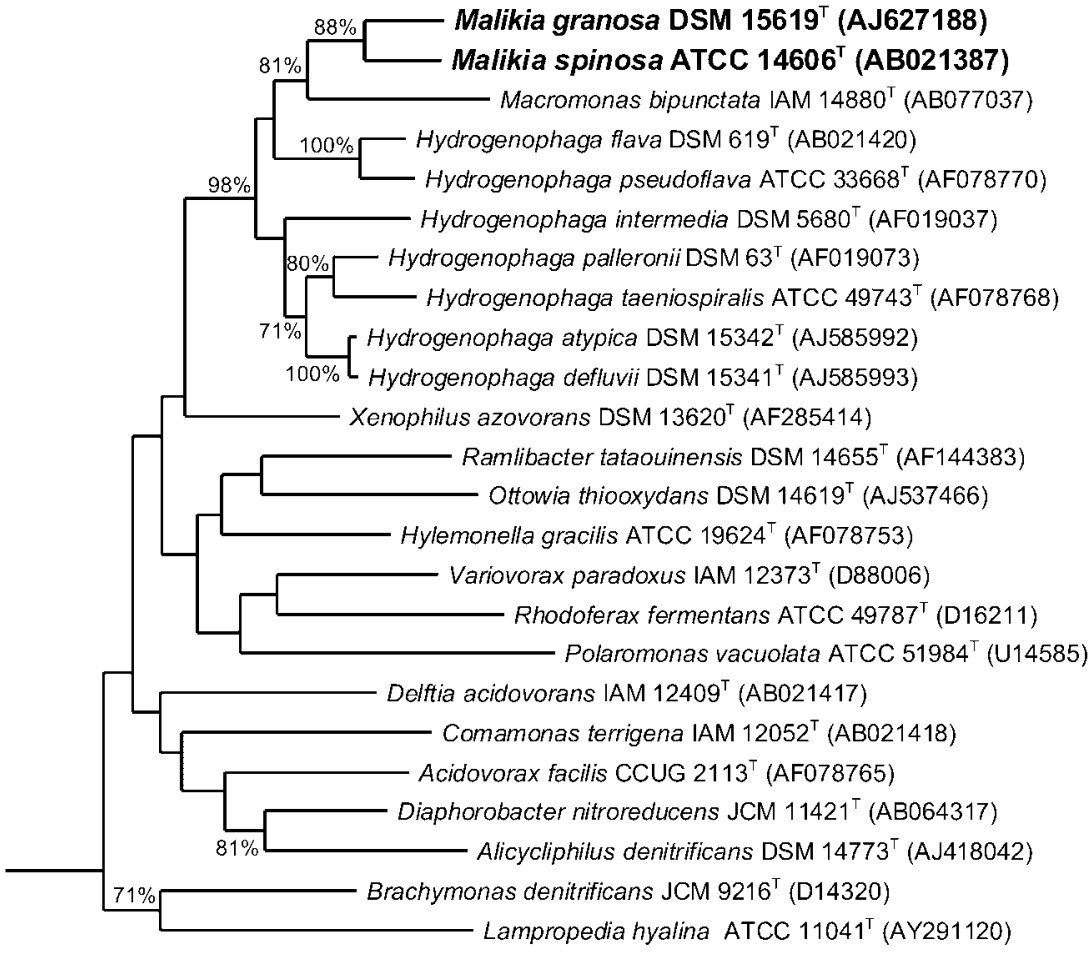

$5 \%$
Fig. 2. Phylogenetic dendrogram illustrating the position of the newly proposed genus Malikia among representatives of the Comamonadaceae. With the exception of the genera Macromonas and Hydrogenophaga, only $16 \mathrm{~S}$ rRNA gene sequences of recognized type species within the Comamonadaceae were used for tree reconstruction. GenBank/ EMBL/DDBJ accession numbers are given in parentheses. The tree was derived from a distance matrix using the method of Saitou \& Nei (1987) as implemented in the ARB (PHYLIP) package (Ludwig et al., 2004). Phylogenetic distances were calculated as described by Felsenstein (1982). Only bootstrap values above $70 \%$ (1000 bootstrap resamplings for each node) are shown. The sequence of Escherichia coli (GenBank/ EMBL/DDBJ accession no. L10328) was used as an outgroup (not shown). Bar, estimated sequence divergence. source. In addition, the reserve polymer glycogen is probably used as a source for reducing equivalents under anaerobic conditions. Hence, the cycling of reserve polymers provides a selective advantage of PAOs compared to other bacteria. It is assumed that the anaerobic-aerobic cycling of biomass during the EBPR process leads to selective enrichment of PAOs under the feast-famine regime in EBPR plants (Serafim et al., 2002). Use of intracellular polymers via the process described above is probably more efficient and faster as a complete metabolic switch from aerobiosis to anaerobiosis, as observed in many facultatively anaerobic, denitrifying bacteria isolated from wastewater.

The accumulation of poly-P and PHAs in strain $\mathrm{P}^{\mathrm{T}}$ was studied under various conditions in order to reveal the possible mechanisms that regulate synthesis of reserve polymers in this strain. The results were compared to the accumulation of reserve polymers in phylogenetically related bacteria. Although it is difficult to identify true PAOs involved in the EBPR process based solely on ex situ experiments, the results obtained should provide valuable taxonomic information regarding the internal metabolism in strain $\mathrm{P}^{\mathrm{T}}$ compared to related bacteria.

In these experiments a simple freshwater medium based on the SFW medium of Spring et al. (2004) was used. The modified SFW medium contained, per litre of distilled water: $0.8 \mathrm{~g} \mathrm{~K}_{2} \mathrm{HPO}_{4}, 0.3 \mathrm{~g} \mathrm{KH}_{2} \mathrm{PO}_{4}, 0.4 \mathrm{~g} \mathrm{MgSO}_{4} .7 \mathrm{H}_{2} \mathrm{O}$, $2 \cdot 0 \mathrm{ml}$ trace elements solution (Vishniac \& Santer, 1957),
$1.0 \mathrm{ml}$ selenite/tungstate solution (Tschech \& Pfennig, 1984), $0 \cdot 1 \mathrm{~g}$ yeast extract (Difco) and $10 \cdot 0 \mathrm{ml}$ vitamins solution (Wolin et al., 1963), to a final $\mathrm{pH}$ of $7 \cdot 2$. Substrates and a source of bound nitrogen $\left(\mathrm{NH}_{4} \mathrm{Cl}\right)$ were added after autoclaving at the concentrations indicated below. Anoxic media were prepared by applying the anaerobe culture technique of Hungate (1950) with the modifications introduced by Bryant (1972).

No growth of strain $\mathrm{P} 1^{\mathrm{T}}$ and $P$. spinosa ATCC $14606^{\mathrm{T}}$ was observed on substrates in modified SFW medium lacking vitamins or yeast extract, indicating that both strains cannot proliferate without growth factors. To study the effect of nitrogen limitation on the accumulation of reserve polymers in strain $\mathrm{P}^{\mathrm{T}}$, the modified SFW medium was supplemented with $2 \cdot 0 \mathrm{~g}$ sodium acetate $1^{-1}$, but not with $\mathrm{NH}_{4} \mathrm{Cl}$. Hence, the only source of bound nitrogen in this medium was $0 \cdot 1 \mathrm{~g}$ yeast extract $1^{-1}$. A loopful of $\mathrm{P} 1^{\mathrm{T}}$ cells grown on R2A agar plates was transferred to this medium and incubated for $24 \mathrm{~h}$. Cells incubated under nitrogen limitation were viewed by phase-contrast microscopy to detect visible inclusions and were tested for poly-P accumulation with Neisser staining. If visible inclusions were observed, the presence of PHA was subsequently confirmed by staining with Nile Blue. In $\mathrm{P}^{\mathrm{T}}$ cells grown on R2A agar, generally only low to moderate amounts of poly-P and PHA could be detected by the respective staining procedures. In contrast, incubation under nitrogen limitation resulted in the accumulation of large amounts 
of PHA in the form of highly refractile granules, whereas poly-P was no longer detectable within the cells. A photomicrograph illustrating the absence of poly- $\mathrm{P}$ in nitrogen-starved cells by Neisser staining is available as supplementary Fig. C(a) in IJSEM Online. Interestingly, no accumulation of PHAs was observed in the same medium under anoxic or micro-oxic conditions (gas atmosphere containing $1 \%$ oxygen).

In a complementary experiment, cells of strain $\mathrm{P}^{\mathrm{T}}$ were incubated in modified SFW medium containing $0.4 \mathrm{~g}$ $\mathrm{NH}_{4} \mathrm{Cl} \mathrm{l}^{-1}$ as nitrogen source, but no acetate. After $24 \mathrm{~h}$ incubation, intracellular PHAs were almost completely degraded and large amounts of intracellular poly-P had accumulated. A photomicrograph illustrating the storage of poly-P in carbon-starved cells by Neisser staining is available as supplementary Fig. C(b) in IJSEM Online.

The above experiments imply that the accumulation of reserve compounds in this strain depends largely on the lack of nitrogen or carbon in the medium. However, to determine if this strain could represent a typical PAO, more laborious analyses would be necessary following incubations under alternate anaerobic/oxic conditions, for example as described by Stante et al. (1997).

Similar results were obtained with P. spinosa ATCC $14606^{\mathrm{T}}$. The only difference was that acetate could not be utilized for the production of PHAs. However, acetate could be replaced with the substrate maltose, which was also effective in inducing the production of PHAs under nitrogen limitation.

In similar experiments with all known type strains of the genus Hydrogenophaga, the same general conditions were effective among species of this genus in the induction of reserve polymers as in strains $\mathrm{P}^{\mathrm{T}}$ and $P$. spinosa ATCC $14606^{\mathrm{T}}$. However, the results were not always clear-cut; several strains showed only weak growth under conditions of nitrogen limitation and PHA accumulation depended strongly on the carbon source used. In most strains a significant accumulation of PHAs was only observed with 3-hydroxybutyrate as substrate.

In Macromonas bipunctata, although closely related with the above-mentioned species, the production of intracellular reserve compounds seemed to be regulated in a different way. In this species, nitrogen limitation obviously had no effect on the production of PHAs. In contrast, the accumulation of PHAs in Macromonas bipunctata DSM $12705^{\mathrm{T}}$ was dependent upon the carbon source, with acetate being most effective (see also Dubinina \& Grabovich, 1984). Under aerobic conditions storage of poly-P was almost constitutive instead of being induced by the deprivation of nutrients. In a preliminary experiment it was shown that a shift from aerobic to anaerobic incubation conditions led to reduced amounts of intracellular poly-P. Although these experiments were only performed with cultures grown on R2A agar plates and the amount of intracellular poly-P was only estimated by visual inspection after Neisser staining, the results obtained may indicate that poly- $\mathrm{P}$ could be utilized by Macromonas bipunctata DSM $12705^{\mathrm{T}}$ under conditions of low oxygen concentrations. Regardless, the internal metabolism of reserve polymers in Macromonas bipunctata DSM $12705^{\mathrm{T}}$ is clearly different from the metabolic type found in the closely related strains $\mathrm{P}^{\mathrm{T}}$ and P. spinosa ATCC $14606^{\mathrm{T}}$ and hence represents a trait of taxonomic relevance.

From the results detailed above, it can be concluded that strain $\mathrm{P}^{\mathrm{T}}$ represents a novel taxon within the family Comamonadaceae, for which we propose the name Malikia granosa gen. nov., sp. nov. The proposal of a new genus seems justified based on the results of a polyphasic approach including biochemical, physiological and genotypic methods. It is further proposed to transfer the misclassified species Pseudomonas spinosa to Malikia gen. nov., as Malikia spinosa comb. nov. Characteristics that differentiate the new genus Malikia from the most closely related taxa of the Comamonadaceae are listed in Table 1.

\section{Description of Malikia gen. nov.}

Malikia (Ma.li'ki.a. N.L. fem. n. Malikia named after Kuhrsheed A. Malik, for his contributions to our knowledge of the cultivation and taxonomy of hydrogen-oxidizing and polyhydroxyalkanoate-accumulating proteobacteria).

Gram-negative, rod-shaped cells, motile by polar flagella. PHAs and poly-Ps are stored intracellulary as reserve materials. Endospores or cysts are not formed. Strictly aerobic; catalase- and oxidase-positive. Not able to grow autotrophically or phototrophically. Not able to fix molecular nitrogen. Growth factors are required. Mesophilic. Restricted to freshwater habitats. No growth above $1 \%$ $(\mathrm{w} / \mathrm{v}) \mathrm{NaCl}$. Major respiratory lipoquinone is ubiquinone 8 (Q-8). Major cellular fatty acids are $16: 1 \omega 7 c, 16: 0$ and $18: 1 \omega 7 c$. The only detectable hydroxylated fatty acid is 8:0 3-OH. Cyclopropane-substituted fatty acids are not present. Phylogenetically affiliated to the Comamonadaceae within the $\beta$-Proteobacteria. The DNA $\mathrm{G}+\mathrm{C}$ content of the type species is $67 \mathrm{~mol} \%$ (HPLC).

The type species is Malikia granosa.

\section{Description of Malikia granosa sp. nov.}

Malikia granosa (gra.no'sa. L. fem. adj. granosa granular).

Cells are straight to slightly curved rods with rounded ends, $1 \cdot 3 \mu \mathrm{m}$ wide and $3 \cdot 5-6 \mu \mathrm{m}$ long, occurring singly, in pairs or in short chains. Occasionally filaments up to $50 \mu \mathrm{m}$ long are formed. Motile by one to two polar flagella. Under conditions of nitrogen limitation cells accumulate large amounts of PHAs that are visible as highly refractile granules by phase-contrast microscopy. Poly-Ps are accumulated under conditions of carbon starvation. Colonies appear after $24 \mathrm{~h}$ on R2A agar and reach approximately $2 \mathrm{~mm}$ in diameter after 2 days incubation. 
They are smooth, circular, raised, cream-white and translucent. After several days colonies appear mucoid owing to the formation of extracellular slime. No diffusible pigments are formed. Growth in liquid medium is homogeneous without formation of visible aggregates. Temperature and $\mathrm{pH}$ optima for growth are $35^{\circ} \mathrm{C}$ and $6 \cdot 5-7 \cdot 0$, respectively. The upper temperature limit for growth is about $40^{\circ} \mathrm{C}$. Growth occurs in media containing $0.5 \%(\mathrm{w} / \mathrm{v}) \mathrm{NaCl}$ but not $1 \%(\mathrm{w} / \mathrm{v}) \mathrm{NaCl}$. Substrates utilized for growth: acetate, adipate, benzoate, gluconate, DL-3-hydroxybutyrate, DLlactate, L-malate, propionate, pyruvate, D-mannitol, Dglucose, D-mannose, sucrose and L-proline. Substrates not utilized for growth: citrate, fumarate, glycolate, glyoxylate, malonate, oxaloacetate, 2-oxoglutarate, succinate, adonitol, glycerol, arabinose, D-galactose, D-fructose, D-maltose, lactose, L-glutamate and L-histidine. Nitrate is reduced to nitrite. Hydrogen cannot be utilized for chemolithoautotrophic growth. Thiosulfate is not oxidized. The DNA G + C content is $67 \mathrm{~mol} \%$ (HPLC).

The type strain, $\mathrm{P} 1^{\mathrm{T}}\left(=\mathrm{DSM} 15619^{\mathrm{T}}=\mathrm{JCM} 12706^{\mathrm{T}}=\mathrm{CIP}\right.$ $108194^{\mathrm{T}}$ ), was isolated from activated sludge of a highload basin of a municipal wastewater treatment plant in Munich, Germany.

\section{Description of Malikia spinosa comb. nov.}

Malikia spinosa (spi.no'sa. L. adj. spinosa thorny, spiny).

Basonym: Pseudomonas spinosa Leifson 1962 (Approved Lists 1980).

The results of this study confirm to a large extent the data provided by Leifson (1962) in the original description. However, additional data obtained in this study make an emendation of the species description necessary. Cells are straight to slightly curved rods with rounded ends, $1 \cdot 1 \mu \mathrm{m}$ wide and 3-6 $\mu \mathrm{m}$ long, occurring singly, in pairs or in short chains. Occasionally filaments up to $50 \mu \mathrm{m}$ long are formed. Motile by one to three polar flagella. Under conditions of nitrogen limitation cells accumulate large amounts of PHAs that are visible as highly refractile granules by phase-contrast microscopy. Poly-Ps are accumulated under conditions of carbon starvation. Colonies appear after $24 \mathrm{~h}$ on R2A agar and reach approximately $1 \mathrm{~mm}$ in diameter after 2 days incubation. They are smooth, circular, raised, cream-white and translucent. After several days colonies appear mucoid owing to the formation of extracellular slime. No diffusible pigments are formed. Growth in liquid medium is homogeneous without formation of visible aggregates. Temperature and $\mathrm{pH}$ optima for growth are $32^{\circ} \mathrm{C}$ and $7 \cdot 5-8 \cdot 0$, respectively. The upper temperature limit for growth is about $36^{\circ} \mathrm{C}$. Growth in media containing $1 \%$ $(\mathrm{w} / \mathrm{v}) \mathrm{NaCl}$ is weak; no growth occurs above $1 \%(\mathrm{w} / \mathrm{v})$ $\mathrm{NaCl}$. Substrates utilized for growth: adipate, gluconate, fumarate, L-malate, D-mannitol, D-glucose, D-maltose and sucrose. Substrates not utilized for growth: acetate, benzoate, citrate, glycolate, glyoxylate, DL-lactate, malonate, propionate, pyruvate, oxaloacetate, 2-oxoglutarate, succinate, adonitol, glycerol, arabinose, D-galactose, D-fructose, D-mannose, lactose, L-glutamate, L-histidine and L-proline. Nitrate is reduced to nitrite. Hydrogen cannot be utilized for chemolithoautotrophic growth. Thiosulfate is not oxidized. The DNA G + C content is $66 \mathrm{~mol} \%$ (HPLC).

Isolated from river water (DuPage River, IL, USA). The type strain is ATCC $14606^{\mathrm{T}}\left(=\mathrm{DSM} 15801^{\mathrm{T}}\right)$.

\section{Acknowledgements}

We are grateful to A. Schütze for testing chemolithoautotrophic growth of the strains $\mathrm{P}^{\mathrm{T}}$, Pseudomonas spinosa ATCC $14606^{\mathrm{T}}$ and Macromonas bipunctata DSM $12705^{\mathrm{T}}$. We thank R. M. Kroppenstedt for help in interpretation of fatty acid data, J. Euzéby for his advice in naming of a novel species and N. Lee for critical reading of the manuscript.

\section{References}

Blackall, L. L., Crocetti, G. R., Saunders, A. M. \& Bond, P. L. (2002). A review and update of the microbiology of enhanced biological phosphorus removal in wastewater treatment plants. Antonie van Leeuwenhoek 81, 681-691.

Bryant, M. P. (1972). Commentary on the Hungate technique for the culture of anaerobic bacteria. Am J Clin Nutr 25, 1324-1328.

Cashion, P., Holder-Franklin, M. A., McCully, J. \& Franklin, M. (1977). A rapid method for the base ratio determination of bacterial DNA. Anal Biochem 81, 461-466.

De Ley, J., Cattoir, H. \& Reynaerts, A. (1970). The quantitative measurement of DNA hybridization from renaturation rates. Eur J Biochem 12, 133-142.

Dubinina, G. A. \& Grabovich, M. Y. (1984). Isolation, cultivation, and characteristics of Macromonas bipunctata. Microbiology (English translation of Mikrobiologiya) 53, 610-617.

Felsenstein, J. (1982). Numerical methods for inferring phylogenetic trees. Q Rev Biol 57, 379-404.

Ginige, M. P., Hugenholtz, P., Daims, H., Wagner, M., Keller, J. \& Blackall, L. L. (2004). Use of stable-isotope probing, full-cycle rRNA analysis, and fluorescence in situ hybridization-microautoradiography to study a methanol-fed denitrifying microbial community. Appl Environ Microbiol 70, 588-596.

Hesselmann, R. P., Werlen, C., Hahn, D., van der Meer, J. R. \& Zehnder, A. J. (1999). Enrichment, phylogenetic analysis and detection of a bacterium that performs enhanced biological phosphate removal in activated sludge. Syst Appl Microbiol 22, 454-465.

Hungate, R. E. (1950). The anaerobic mesophilic cellulolytic bacteria. Bacteriol Rev 14, 1-49.

Jenkins, D., Richards, M. G. \& Daigger, G. T. (1993). Manual on the Causes and Control of Activated Sludge Bulking and Foaming, 2nd edn. London: Lewis.

Juretschko, S., Loy, A., Lehner, A. \& Wagner, M. (2002). The microbial community composition of a nitrifying-denitrifying activated sludge from an industrial sewage treatment plant analyzed by the full-cycle rRNA approach. Syst Appl Microbiol 25, 84-99.

Kämpfer, P. \& Kroppenstedt, R. M. (1996). Numerical analysis of fatty acid patterns of coryneform bacteria and related taxa. Can J Microbiol 42, 989-1005.

Kämpfer, P., Steiof, M. \& Dott, W. (1991). Microbiological characterization of a fuel-oil contaminated site including numerical 
identification of heterotrophic water and soil bacteria. Microb Ecol 21, 227-251.

Kämpfer, P., Denner, E. B. M., Meyer, S., Moore, E. R. B. \& Busse, H.-J. (1997). Classification of "Pseudomonas azotocolligans" Anderson 1955, 132, in the genus Sphingomonas as Sphingomonas trueperi sp. nov. Int J Syst Bacteriol 47, 577-583.

Kämpfer, P., Schulze, R., Jäckel, U., Malik, K. A., Amann, R. \& Spring, S. (2005). Hydrogenophaga defluvii sp. nov. and Hydrogenophaga atypica sp. nov., isolated from activated sludge. Int J Syst Evol Microbiol 55, 341-344.

Lee, N., Nielsen, P. H., Andreasen, K. H., Juretschko, S., Nielsen, J. L., Schleifer, K.-H. \& Wagner, M. (1999). Combination of fluorescent in situ hybridization and microautoradiography - a new tool for structure-function analyses in microbial ecology. Appl Environ Microbiol 65, 1289-1297.

Lee, N., Nielsen, P. H., Aspegren, H., Henze, M., Schleifer, K.-H. \& la Cour Jansen, J. (2003). Long-term population dynamics and in situ physiology in activated sludge systems with enhanced biological phosphorus removal operated with and without nitrogen removal. Syst Appl Microbiol 26, 211-227.

Leifson, E. (1962). Pseudomonas spinosa n. sp. Int Bull Bacteriol Nomencl Taxon 12, 89-92.

Ludwig, W., Strunk, O., Westram, R. \& 29 other authors (2004). ARB: a software environment for sequence data. Nucleic Acids Res 32, 1363-1371.

Malik, K. A. \& Schlegel, H. G. (1981). Chemolithoautotrophic growth of bacteria able to grow under $\mathrm{N}_{2}$-fixing conditions. FEMS Microbiol Lett 11, 63-67.

Manz, W., Wagner, M., Amann, R. \& Schleifer, K.-H. (1994). In situ characterization of the microbial consortia active in two wastewater treatment plants. Water Res 28, 1715-1723.

Monciardini, P., Cavaletti, L., Schumann, P., Rohde, M. \& Donadio, S. (2003). Conexibacter woesei gen. nov., sp. nov., a novel representative of a deep evolutionary line of descent within the class Actinobacteria. Int J Syst Evol Microbiol 53, 569-576.

Ostle, A. G. \& Holt, J. G. (1982). Nile Blue A as a fluorescent stain for poly- $\beta$-hydroxybutyrate. Appl Environ Microbiol 44, 238-241.

Ouverney, C. C. \& Fuhrman, J. A. (1999). Combined microautoradiography-16S rRNA probe technique for determination of radioisotope uptake by specific microbial cell types in situ. Appl Environ Microbiol 65, 1746-1752.

Purkhold, U., Pommerening-Röser, A., Juretschko, S., Schmid, M. C., Koops, H. P. \& Wagner, M. (2000). Phylogeny of all recognized species of ammonia-oxidizers based on comparative 16S rRNA and amoA sequence analysis: implications for molecular diversity surveys. Appl Environ Microbiol 66, 5368-5382.

Reasoner, D. J. \& Geldreich, E. E. (1985). A new medium for the enumeration and subculture of bacteria from potable water. Appl Environ Microbiol 49, 1-7.

Saitou, N. \& Nei, M. (1987). The neighbor-joining method: a new method for reconstructing phylogenetic trees. Mol Biol Evol 4, 406-425.

Schulze, R., Spring, S., Amann, R., Huber, I., Ludwig, W., Schleifer, K.-H. \& Kämpfer, P. (1999). Genotypic diversity of Acidovorax strains isolated from activated sludge and description of Acidovorax defluvii sp. nov. Syst Appl Microbiol 22, 205-214.

Serafim, L. S., Lemos, P. C., Levantesi, C., Tandoi, V., Santos, H. \& Reis, M. A. M. (2002). Methods for detection and visualization of intracellular polymers stored by polyphosphate-accumulating microorganisms. J Microbiol Methods 51, 1-18.

Seviour, R. J., Mino, T. \& Onuki, M. (2003). The microbiology of biological phosphorus removal in activated sludge systems. FEMS Microbiol Rev 27, 99-127.

Snaidr, J., Amann, R., Huber, I., Ludwig, W. \& Schleifer, K.-H. (1997). Phylogenetic analysis and in situ identification of bacteria in activated sludge. Appl Environ Microbiol 63, 2884-2896.

Spring, S., Kämpfer, P. \& Schleifer, K. H. (2001). Limnobacter thiooxidans gen. nov., sp. nov., a novel thiosulfate-oxidizing bacterium isolated from freshwater lake sediment. Int $J$ Syst Evol Microbiol 51, 1463-1470.

Spring, S., Jäckel, U., Wagner, M. \& Kämpfer, P. (2004). Ottowia thiooxydans gen. nov., sp. nov., a novel facultatively anaerobic, $\mathrm{N}_{2} \mathrm{O}-$ producing bacterium isolated from activated sludge, and transfer of Aquaspirillum gracile to Hylemonella gracilis gen. nov., comb. nov. Int J Syst Evol Microbiol 54, 99-106.

Stante, L., Cellamare, C. M., Malaspina, F., Bortone, G. \& Tolche, A. (1997). Biological phosphorus removal by pure culture of Lampropedia spp. Water Res 31, 1317-1324.

Tschech, A. \& Pfennig, N. (1984). Growth yield increase linked to caffeate reduction in Acetobacterium woodii. Arch Microbiol 137, 163-167.

Vishniac, W. \& Santer, M. (1957). The Thiobacilli. Bacteriol Rev 21, 195-213.

Wagner, M. \& Amann, R. (1997). Molecular techniques for determining microbial community structures in activated sludge. In Microbial Community Analysis: the Key to the Design of Bacterial Wastewater Treatment Systems, pp. 61-72. IAWQ Scientific Technical Report no. 5. Edited by T. E. Cloete \& N. Y. O. Muyima. Cambridge: Cambridge University Press.

Wagner, M. \& Loy, A. (2002). Bacterial community composition and function in sewage treatment systems. Curr Opin Biotechnol 13, 218-227.

Wagner, M., Amann, R., Lemmer, H. \& Schleifer, K.-H. (1993). Probing activated sludge with oligonucleotides specific for Proteobacteria: inadequacy of culture-dependent methods for describing microbial community structure. Appl Environ Microbiol 59, 1520-1525.

Wagner, M., Amann, R., Kämpfer, P., Assmus, B., Hartmann, A., Hutzler, P., Springer, N. \& Schleifer, K.-H. (1994a). Identification and in situ detection of gram-negative filamentous bacteria in activated sludge. Syst Appl Microbiol 17, 405-417.

Wagner, M., Erhart, R., Manz, W., Amann, R., Lemmer, H., Wedi, D. \& Schleifer, K. H. (1994b). Development of an rRNA-targeted oligonucleotide probe specific for the genus Acinetobacter and its application for in situ monitoring in activated sludge. Appl Environ Microbiol 60, 792-800.

Wallner, G., Erhart, R. \& Amann, R. (1995). Flow cytometric analysis of activated sludge with rRNA-targeted probes. Appl Environ Microbiol 61, 1859-1866.

Wolin, E. A., Wolin, M. J. \& Wolfe, R. S. (1963). Formation of methane by bacterial extracts. J Biol Chem 238, 2882-2886.

Yokota, A., Akagawa-Matsushita, M., Hiraishi, A., Katayama, Y., Urakami, T. \& Yamasato, K. (1992). Distribution of quinone systems in microorganisms: Gram-negative eubacteria. Bull Jpn Fed Cult Coll 8, 136-171. 